COMUNICAÇÃO CIENTÍFICA

\title{
FLUORESCÊNCIA DA CLOROFILA $a$ EM FOLHAS DE TANGERINEIRA 'PONKAN' E LIMEIRA ÁCIDA 'TAHITI' SUBMETIDAS AO ESTRESSE HIIDRICO ${ }^{1}$
}

\author{
MARIA DO CÉU MONTEIRO DA CRUZ², DALMO LOPES DE SIQUEIRA ${ }^{3}$, \\ LUIZ CARLOS CHAMHUM SALOMÃO ${ }^{3}$, PAULO ROBERTO CECON $^{4}$
}

RESUMO - O trabalho foi realizado com o objetivo de avaliar o estresse causado por deficiência hídrica para induzir o florescimento sobre a fluorescência da clorofila $a$ em tangerineira 'Ponkan' e limeira ácida 'Tahiti'. As plantas foram enxertadas sobre o limoeiro 'Cravo', conduzidas em câmara de crescimento sob condições controladas. O estresse causado pela deficiência hídrica submetido à tangerineira 'Ponkan' e à limeira ácida 'Tahiti' reduziu a eficiência quântica potencial do fotossistema II $\left(\mathrm{F}_{\mathrm{v}} / \mathrm{F}_{\mathrm{m}}\right)$. Após a irrigação, as plantas apresentaram valores dos parâmetros de fluorescência similares àqueles verificados antes do estresse submetido por deficiência hídrica.

Termos para indexação: Citrus reticulata Blanco, Citrus latifolia Tanaka, eficiência do fotossistema II. Consciência.

\section{CHLOROPHYLL $a$ FLUORESCENCE IN LEAVES OF 'PONKAN' MANDARIN AND THE 'TAHITI' ACID LIME SUBMITTED TO WATER STRESS}

\begin{abstract}
The research was carried out with the aim to evaluate the stress caused by water deficiency on a chlorophyll $a$ fluorescence in 'Ponkan' mandarin and 'Tahiti' acid lime plants. The plants were grafted on Rangpur lime submitted to water stress in growth chamber under controlled conditions for induce the flowering. the stress caused by water deficiency submitted in plants of mandarin 'Ponkan' and 'Tahiti' lime decreased the potential quantum efficiency of photosystem II $\left(\mathrm{F}_{\mathrm{v}} / \mathrm{F}_{\mathrm{m}}\right)$. After the irrigation the plants showed fluorescence parameters values similar to those prior to stress submitted by water deficiency.
\end{abstract}

Index terms: Citrus reticulata Blanco, Citrus latifolia Tanaka, photosystem II efficiency.

Nos citros, o estresse causado por deficiência hídrica é apontado por vários autores (Davenport, 1990; Krajewski \& Rabe, 1995; Pire \& Rojas, 1999) como um dos fatores que atuam na indução do florescimento das plantas. No entanto, o cultivo das plantas sob condições de estresse hídrico pode causar distúrbios fisiológicos em função da redução do potencial hídrico.

Uma forma de monitorar a resposta das plantas ao déficit hídrico tem sido a utilização de medidas da fluorescência da clorofila $a$ associada ao fotossistema II (Baker, 1993; Newton \& McBeath, 1996).

Em condições de ambientes estressantes ocorre o decréscimo característico na eficiência quântica potencial do fotossistema II, podendo ser detectada pela queda na relação $\mathrm{F}_{\mathrm{v}} / \mathrm{F}_{\mathrm{m}}$ (Krause \& Weis, 1991).
A eficiência fotossintética máxima das plantas é dada pela relação $F_{v} / F_{m}$, em que $F_{m}$ é a fluorescência máxima e $F_{v}$ é a fluorescência variável, que é obtida pela diferença entre $\mathrm{F}_{\mathrm{m}}-\mathrm{F}_{0} . \mathrm{O} \mathrm{F}_{0}$ representa a fluorescência inicial, correspondente à fração da energia absorvida pelo complexo-antena e não é transmitida, ou seja, não é absorvida pelos pigmentos fotossintéticos (Rascher et al., 2000). Dessa forma, a avaliação desses parâmetros é útil para mensurar as alterações na capacidade fotossintética das plantas em decorrência de estresse causado por deficiência hídrica.

Sob condições de déficit hídrico, ocorre redução da concentração intercelular de $\mathrm{CO}_{2}$, em razão do fechamento estomático, gerando decréscimos na assimilação do $\mathrm{CO}_{2}$ e na eficiência quântica do fotossistema II (Baker, 1993). Além disso, podem ocorrer limitações em componentes não estomáticos, com danos nos centros de reação do fotossistema

\footnotetext{
${ }^{1}$ (Trabalho 073-08). Recebido em: 25-03-2008. Aceito para publicação em: 30-04-2009.

${ }^{2}$ Eng. Agr., Doutoranda em Fitotecnia, UfLA. Cx. Postal 37, CEP 37200-000. Lavras-MG. Bolsista do CNPq, m_mariceu@yahoo.com.br

${ }^{3}$ Eng. Agr., Dr., Professor Adjunto, DFT-UFV, CEP 36570-000. Viçosa-MG. Email: siqueira@ufv.br; 1salomao@ufv.br

${ }^{4}$ Eng. Agr., Dr. Professor Adjunto, DPI-UFV, CEP 36570-000, Viçosa-MG. cecon@dpi.ufv.br
} 
II, os quais podem apresentar reversão parcial após reidratação (Angelopoulos et al., 1996).

As medições da fluorescência da clorofila $a$ têm sido difundidas por ser um método que, além de não destrutivo, permite a análise qualitativa e quantitativa da absorção e aproveitamento da energia luminosa pelo fotossistema II e possíveis relações com a capacidade fotossintética (Mouget \& Tremblin, 2002). São frequentemente utilizadas para avaliar a eficiência fotoquímica e o estado fisiológico geral das plantas (Baker \& Rosenqvist, 2004).

O trabalho foi realizado com o objetivo de avaliar o estresse causado por deficiência hídrica sobre a fluorescência da clorofila $a$ em tangerineira 'Ponkan' e limeira ácida 'Tahiti'.

As avaliações foram realizadas em plantas de tangerineira 'Ponkan' (Citrus reticulata Blanco) e limeira ácida 'Tahiti' (Citrus latifolia Tanaka), enxertadas sobre limoeiro 'Cravo' (Citrus limonia Osbeck), com três anos de idade e cultivadas em vasos de cinco litros, contendo substrato comercial Plantmax ${ }^{\circledR}$. As plantas foram conduzidas em câmara de crescimento, com temperatura controlada $\left(25^{\circ} \mathrm{C}\right.$ dia/ $20^{\circ} \mathrm{C}$ noite), e fotoperíodo de 16 horas de luz, com fluxo de fótons fotossintético (FFF) de aproximadamente $170 \mu \mathrm{mol} \mathrm{m} \mathrm{m}^{-2} \mathrm{~s}^{-1}$, no período de fevereiro a junho de 2004, época em que as plantas estavam no estádio de repouso vegetativo.

As plantas foram dispostas no delineamento de blocos casualizados, com quatro repetições. Foram submetidos três períodos de estresse mediante a deficiência hídrica de: 15; 25 e 35 dias de estresse, e o controle (plantas que foram irrigadas), e duas cultivares de citros: tangerineira 'Ponkan' e limeira ácida 'Tahiti'.

O estresse causado por deficiência hídrica foi aplicado por suspensão da irrigação de acordo com os tratamentos. Os vasos foram cobertos com sacos plásticos pretos para evitar as perdas de água no substrato por evaporação. No final de cada período de estresse, foi determinado o potencial hídrico $\left(\Psi_{\mathrm{w}}\right)$ foliar utilizando-se da bomba de Scholander, modelo "Soilmoisture 3000 ". As determinações foram realizadas em folhas maduras, de idade similar e mesma disposição no caule. Ao final de cada período de estresse, a irrigação das plantas foi retomada.

As determinações da fluorescência da clorofila $a$ foram realizadas na metade do limbo da segunda folha totalmente expandida, contada a partir do ápice, antes da imposição do estresse causado pela deficiência hídrica e aos 15; 25; 35 e 45 dias, no período entre 8 e 10 horas da manhã. Antes de cada avaliação, as folhas foram adaptadas ao escuro por 30 minutos. Para determinar a fluorescência inicial $\left(\mathrm{F}_{0}\right)$, a fluorescência máxima $\left(\mathrm{F}_{\mathrm{m}}\right)$, fluorescência variável $\left(F_{v}\right)$ e eficiência quântica potencial do fotossistema II $\left(\mathrm{F}_{\mathrm{v}} / \mathrm{F}_{\mathrm{m}}\right)$ foi utilizado um fluorômetro portátil (Plant, Efficiency Analyser, PEA, HANSATECH INTRUMENTS LTD, England).

Após a obtenção dos dados, foi realizada a análise descritiva. relacionando os diferentes períodos de estresse causado pela deficiência hídrica com as variações das fluorescências da clorofila $a$ durante o período avaliado.

O estresse causado por deficiência hídrica imposto à tangerineira 'Ponkan' e à limeira ácida 'Tahiti' causou aumento da $\mathrm{F}_{0}$, em ambas as cultivares, para todos os períodos de estresse (Figura 1). A elevação foi proporcional aos níveis de estresse, a $\mathrm{F}_{0}$ detectada nas folhas de tangerineira 'Ponkan' e 'Tahiti' variou entre 570 e 517 nas plantas irrigadas e entre 1.120 e 1.219 nas plantas submetidas a 35 dias de estresse hídrico, respectivamente. No entanto, após a irrigação das plantas, apresentou valores semelhantes aos observados antes do estresse causado por deficiência hídrica.

Essa diferença pode indicar danos no centro de reação do fotossistema II, possivelmente em função da redução do potencial hídrico foliar (Figura 5). De acordo com Bolhàr-Nordenkampf \& Onquist (1993), o valor da $\mathrm{F}_{0}$ pode aumentar quando os centros de reação do fotossistema II estão comprometidos ou a transferência da energia de excitação da antena para os centros de reação está prejudicada.

Quanto à $\mathrm{F}_{\mathrm{m}}$ (Figura 2), observa-se que houve decréscimo dos valores com a elevação do estresse causado por deficiência hídrica em ambas as cultivares (tangerineira 'Ponkan' e limeira ácida 'Tahiti'). Os percentuais de redução de $\mathrm{F}_{\mathrm{m}}$ nas plantas de 'Ponkan' foi de $25 \%$, e de $14 \%$ na limeira ' Tahiti.

Esse comportamento indica que o decréscimo prolongado da água disponível no solo pode culminar em danos irreversíveis aos tecidos foliares. Pois, à medida que a disponibilidade de água para a planta diminui, a transpiração é reduzida, a senescência é acelerada e as folhas mais velhas sofrem dessecação e, posteriormente, abscisão. As restrições estomáticas no suprimento de $\mathrm{CO}_{2}$, pela falta de água, podem provocar limitações em componentes não estomáticos, com danos nos centros de reação do fotossistema II. Angelopoulos et al. (1996) observaram decréscimos pequenos na capacidade de transporte de elétrons do fotossistema II sob condições de estresse moderado; no entanto, quando as plantas foram submetidas a estresse hídrico severo, houve diminuição expressiva. Esses resultados indicam que o fossistema II foi o principal sítio afetado pelo estresse causado por 
deficiência hídrica.

A variação dos valores da $F_{m}$ nas espécies pode demonstrar variações nas propriedades dos aceptores de elétrons do FSII, causadas por mudanças conformacionais induzidas pelo estresse no principal constituinte do complexo proteico que forma o FSII, a proteína D1 (Bulkhov et al., 1999).

$\mathrm{Na}$ Figura 3, observa-se que a $\mathrm{F}_{\mathrm{v}}$ apresentou queda acentuada com o avanço do período sem irrigação. Esse comportamento foi registrado a partir do $15^{\circ}$ dia após a suspensão da irrigação, alcançando valores mínimos aos 35 dias de estresse. Verificouse ainda que, a partir desse período, todas as plantas de 'Ponkan' apresentaram enrolamento e queda de folhas basais.

A redução nos valores da $F_{v}$ e da $F_{m}$ e a elevação do $\mathrm{F}_{0}$ ocorreram em função do aumento do estresse causado por deficiência hídrica submetido às plantas. Observou-se nas plantas que foram submetidas a 35 dias de deficiência hídrica as maiores alterações das fluorescências, evidenciando que tais parâmetros podem ser utilizados para avaliar o estado fisiológico das plantas no que se refere às mudanças decorrentes de estresse por deficiência hídrica.

As variações da $\mathrm{F}_{0}, \mathrm{~F}_{\mathrm{m}}$ e $\mathrm{F}_{\mathrm{v}}$ contribuíram para a redução da eficiência quântica máxima do FSII $\left(\mathrm{F}_{\mathrm{v}} / \mathrm{F}_{\mathrm{m}}\right)$ em função do estresse causado por deficiência hídrica submetido às plantas. Observou-se que os menores valores da relação $\mathrm{F}_{\mathrm{v}} / \mathrm{F}_{\mathrm{m}}$ ocorreram nas plantas submetidas ao período 35 dias de deficiência hídrica, aumentando após a irrigação das plantas. O menor valor alcançado foi $0,32 \mathrm{em}$ ambas as cultivares (Figura 4), sugerindo que a redução na eficiência quântica do fotossistema II ocorreu em função do estresse a que as plantas foram submetidas. Sob condições normais (não estressante), o valor da eficiência quântica máxima $\mathrm{F}_{\mathrm{v}} / \mathrm{F}_{\mathrm{m}}$, para a maioria das espécies, varia entre 0,78 e 0,83 (Osmond, 1994).

Os baixos valores da relação $\mathrm{F}_{\mathrm{v}} / \mathrm{F}_{\mathrm{m}}$ observados caracterizam danos que podem estar relacionados: à redução da concentração intercelular de $\mathrm{CO}_{2}$, em razão do fechamento estomático (Baker,1993); aumento na peroxidação lipídica em decorrência do desvio do fluxo de elétrons da assimilação de $\mathrm{CO}_{2}$ para a redução de $\mathrm{O}_{2}$ (Lemos Filho, 2000) e queda na atividade fotossintética (Smirnoff, 1993) em função da condição de estresse causado por deficiência hídrica.

Essas características demonstram que o estresse causado por deficiência hídrica às plantas foi severo, observando-se nas plantas submetidas a 35 dias de deficiência hídrica os menores valores da relação $\mathrm{F}_{\mathrm{v}} / \mathrm{F}_{\mathrm{m}}$, e baixo $\Psi \mathrm{w}$ foliar; a tangerineira 'Ponkan' atingiu -3,91 MPa e - a limeira ácida 'Tahiti' 3,22 MPa (Figura 5). Porém, deve-se ressaltar que essa condição de estresse foi reversível, pois, na avaliação realizada 10 dias após a irrigação das plantas, verificou-se recuperação da eficiência quântica do FSII constatada pela elevação da relação $\mathrm{F}_{\mathrm{v}} / \mathrm{F}_{\mathrm{m}}$ (Figura 3 ).

$\mathrm{O}$ decréscimo da relação $\mathrm{F}_{\mathrm{v}} / \mathrm{F}_{\mathrm{m}}$ tem evidenciado a resposta das plantas de citros ao estresse. Em condições de campo, o estresse causado por deficiência hídrica pode ser severo, dada a deficiência hídrica encontrar-se associada a outras condições adversas do ambiente, como temperatura e radiação altas, que podem causar danos mais evidentes à eficiência quântica do fotossistema II (Chaves, 1991). No entanto, deve-se ressaltar que, neste trabalho, o estresse causado por deficiência hídrica submetido às plantas ocorreu sob condições controladas, sem variações de temperatura ao longo do período de avaliação, portanto, provavelmente, pouco ou nenhum dano sobre o fotossistema II tenha permanecido após a irrigação das plantas.

Nas condições do presente estudo, o estresse causado pela deficiência hídrica submetido à tangerineira 'Ponkan' e à limeira ácida 'Tahiti' reduziu a eficiência quântica potencial do fotossistema II $\left(\mathrm{F}_{\mathrm{v}} / \mathrm{F}_{\mathrm{m}}\right)$. Após a irrigação, as plantas apresentaram valores dos parâmetros de fluorescência similares àqueles verificados antes do estresse submetido por deficiência hídrica. 

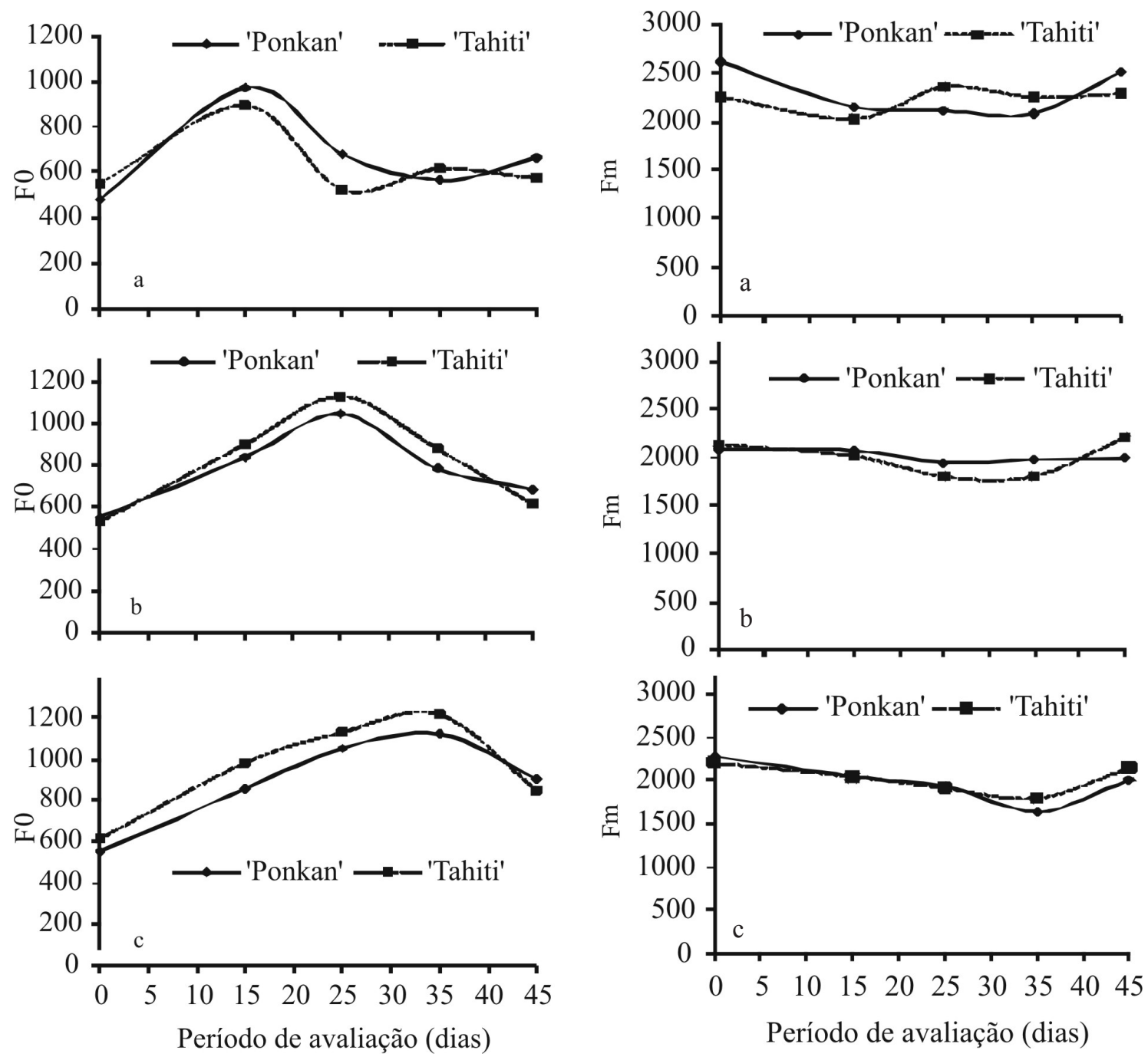

FIGURA 1- Fluorescência inicial $\left(\mathrm{F}_{0}\right)$ em folhas de tangerineira 'Ponkan' e limeira ácida 'Tahiti' submetidas a 15 (a), 25 (b) e 35 (c) dias de deficiência hídrica.

FIGURA 2- Fluorescência máxima $\left(\mathrm{F}_{\mathrm{m}}\right)$ em folhas de tangerineira 'Ponkan' e limeira ácida 'Tahiti' submetidas a 15 (a), 25 (b) e 35 (c) dias de deficiência hídrica. 

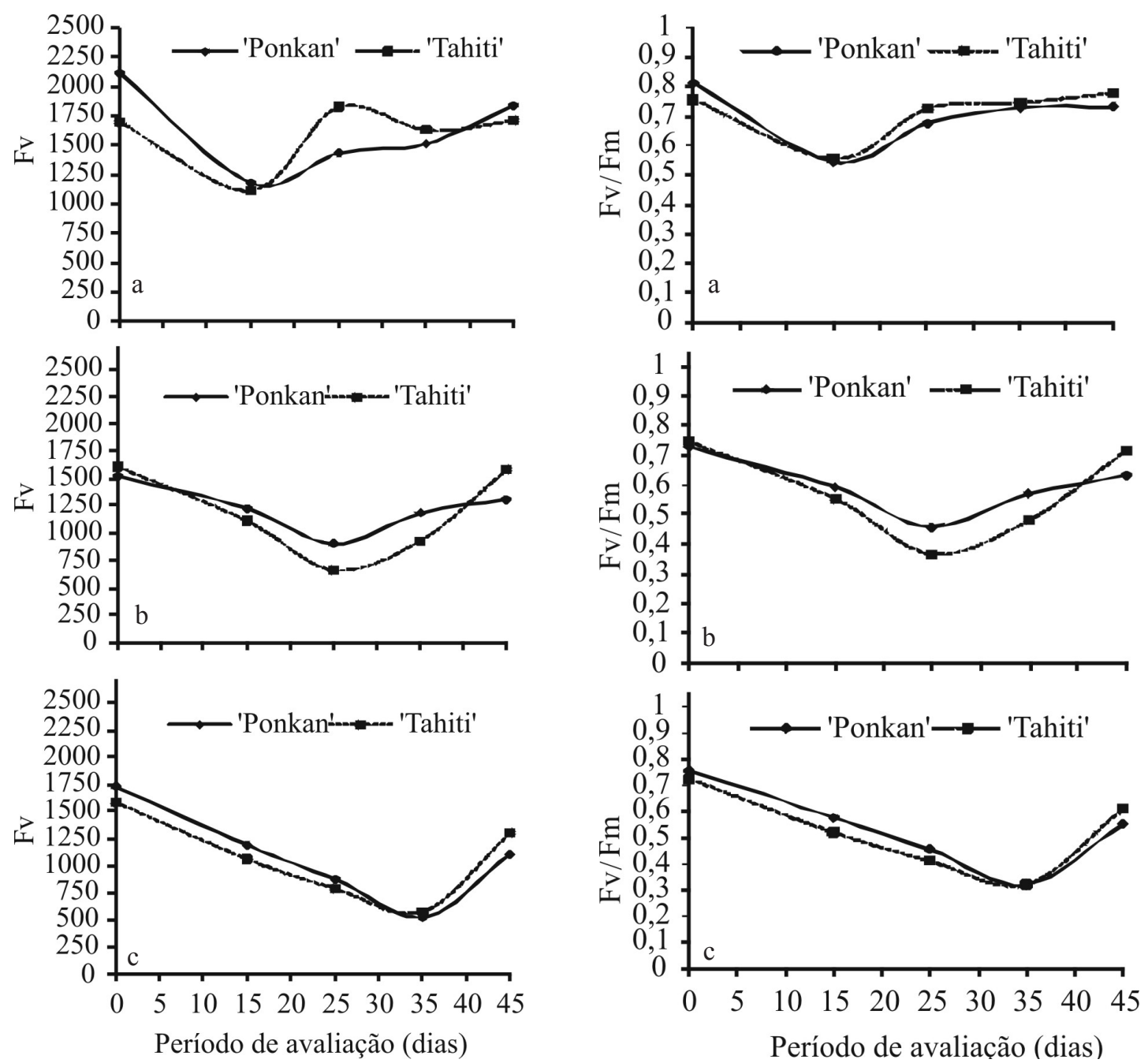

FIGURA 3- Fluorescência variável (Fv) em folhas de tangerineira 'Ponkan' e limeira ácida 'Tahiti' submetidas a 15 (a), 25 (b)

FIGURA 4 - Eficiência do fotossistema II dada pela relação $\mathrm{Fv} / \mathrm{Fm}$ em folhas de tangerineira 'Ponkan' e limeira ácida 'Tahiti' submetidas a 15 (a), 25 (b) e 35 (c) dias de deficiência hídrica. e 35 (c) dias de deficiência hídrica.

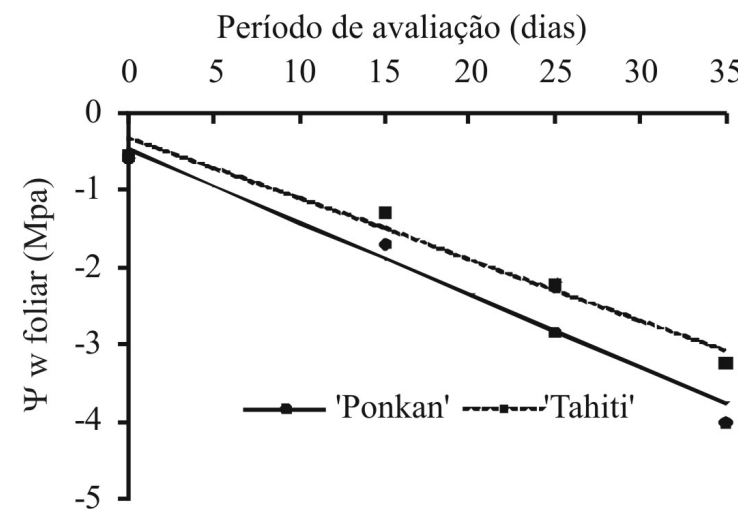

FIGURA 5 - Potencial hídrico foliar em folhas de tangerineira 'Ponkan' e limeira ácida 'Tahiti' submetidas ao estresse causado por deficiência hídrica. 


\section{REFERÊNCIAS}

ANGELOPOULOS, K.; DICHIO, B.; XILOYANNIS, C. Inhibition of photosynthesis in olive trees (Olea europaea L.) during water stress and rewatering. Journal of Experimental Botany, Oxford, v. 47 p. 1093-1100, 1996.

BAKER NR Light-use efficiency and photoinhibition of photosynthesis in plants under environmental stress. In: SMITH, J.A.C.; GRIFFITHS, H. (Eds.). Water deficits plant responses from cell to community, Bios Scientific Publisher, Oxford, 1993. p. 221-235.

BAKER, N.R.; ROSENQVIST, E. Applications of chlorophyll fluorescence can improve crop production strategies: an examination of future possibilities. Journal of Experimental Botany, Oxford, v.55, p.1607-1621, 2004.

BOLHÀR-NORDENKAMPF, H.R.; OQUIST, G. Chlorophyll fluorescence as a toll in photosynthesis research. In: HALL, D.; SCURLOCK, J. M. O.; BOLHÀR-NORDENKAMPF, H. R.; LONG, S. P. (Eds.). Photosynthesis and production in a changing environmental. London: Chapman \& Hall, 1993. p. 193-206.

BULKHOV, N.; WIESE, C.; NEIMANIS, S. et al. Heat sensitivity of chloroplasts and leaves: Leakage of protons from thylakoids and reversible activation of cyclic eletron transport. Photosynthesis Research, New York, v.59, p.81-93, 1999.

CHAVES, M.M. Effects of water deficits on carbon assimilation. Journal of Experimental Botany, Oxford, v.42, n.234, p.1-16, 1991.

DAVENPORT, T. L. Citrus flowering. Horticultural Reviews, New York, v. 12, p. 349-408, 1990.

KRAJEWSKI, A. J.; RABE, E. Citrus flowering: A critical evaluation. Journal of Horticultural
Science, Ashford, v.70, n.3, p. 357-374, 1995.

KRAUSE, G.H.; WEIS, E. Chlorophyll fluorescence and photosynthesis: the basics. Annual Review of Plant Physiology and Plant Molecular Biology, Palo Alto v.42, p.313-349, 1991.

LEMOS-FILHO, J.P. Fotoinibição em três espécies de cerrado (Annona crassifolia, Eugenia dysenterica e Campomanesia adamantium) na estação seca e na chuvosa. Revista Brasileira de Botânica, São Paulo, v. 23, p.45 -50. 2000.

MOUGET, J.; TREMBLIN, G. Suitability of the fluorescence monitoring system (FM, Hansatech) for measurement of photosynthetic characteristics in algae. Aquatic Botany, Amsterdan, v.74, p.219231, 2002.

NEWTON, A.C.; McBEATH, C. The impact of desiccation on chlorophyll fluorescence in detached leaves of six tropical tree species. Photosynthetica, Prague, v. 32, p.491-501. 1996.

OSMOND, C.B. What is photoinhibition? Some insights from comparisons of shade and sun plants. In: BAKER, N.R.; BOWYER, J.R. (Ed.). Photoinhibition of photosynthesis, from molecular mechanisms to the field. Lancaster: Scientific Publishers, 1994. p.1-24.

PIRE, R; ROJAS, E. Effects of drought stress and urea sprays on production of flower and vegetative buds of Tahiti lime. Fuits, Paris, v.54, p. 177-182, 1999.

RASCHER, U.; LIEBIG, M.; LÜTTGE, U. Evaluation of instant light-responses curves of chlorophyll parameters obtained with a portable chlorophyll fluorometer on site in the field. Plant Cell \& Environment, Oxford, v. 23, n. 12, p. 1397-1405, 2000.

SMIRNOFF, N. The role of active oxygen in the response of plants to water deficit and desiccation. New Phytologist, Cambridge, v. 125, p.27-58. 1993. 